\title{
Short Communication: \\ The correlation between foot circumference with the body length, shoulder height, and pelvic width in Sumatran elephants (Elephas maximus sumatranus)
}

\author{
HERY WIJAYANTO ${ }^{1, \bullet}$, DENY SETYO WIBOWO ${ }^{2}$, RINI WIDAYANTI ${ }^{3}$, TRI WAHYU PANGESTININGSIH ${ }^{1}$, \\ WORO DANUR WENDO ${ }^{1}$, MACHMUD ASVAN ${ }^{4}$, ANASTASIA STEPHANIE GUNAWAN ${ }^{1}$, \\ MARCEL WIRABRATA ${ }^{1}$ \\ ${ }^{1}$ Department of Anatomy, Faculty of Veterinary Medicine, Universitas Gadjah Mada. Jl. Fauna No. 2, Karangmalang, Sleman 55281, Yogyakarta, \\ Indonesia. Tel.: +62-274-6492088, Fax.: +62-274-560861, `email: herykh@ugm.ac.id. \\ ${ }^{2}$ Veterinary Science Doctoral Program, Faculty of Veterinary Medicine, Universitas Gadjah Mada. Jl. Fauna No. 2, Karangmalang, Sleman 55281, \\ Yogyakarta, Indonesia \\ ${ }^{3}$ Departement of Biochemistry, Faculty of Veterinary Medicine, Universitas Gadjah Mada. Jl. Fauna No. 2, Karangmalang, Sleman 55281, Yogyakarta, \\ Indonesia \\ ${ }^{4}$ Gembira Loka Zoo. Jl. Kebun Raya No. 2, Rejowinangun, Kotagede, Yogyakarta City 55171, Yogyakarta, Indonesia
}

Manuscript received: 23 April 2021. Revision accepted: 10 June 2021

\begin{abstract}
Wijayanto H, Wibowo DS, Widayanti R, Pangestiningsih TW, Wendo WD, Asvan M, Gunawan AS, Wirabrata M. 2021. Short Communication: The correlation between foot circumference with the body length, shoulder height, and pelvic width in Sumatran elephants (Elephas maximus sumatranus). Biodiversitas 22: 2635-2640. Sumatran elephants' body measurement is essential in conservation practices to perceive health status and determining medication doses. Considering elephants' size, the mahouts doing the recording can easily get harmed during their interaction with their animal. Therefore, easier method to shortening interaction time is urgently needed in estimating elephants' size. The aim of the research is to find out the correlations between forefoot and hindfoot circumference (FFC and HFC) with the body length (BL), shoulder height (SH), and pelvic width (PW) in Sumatran elephants. The correlation formula will very much reduce the time needed to measure the elephant size, since the mahouts only need to measure the foot circumference left by the elephant on the ground to predict BL, SH, and PW. The anatomical data were collected from adult elephants in Aceh, Safari Park Indonesia, Gembira Loka Zoo, Borobudur Park, and PLG Duri Pekanbaru. Measurements were done using modified Vernier calipers and roll meters, referring to standardized methods. The data then calculated using correlation and linearregression test. From the results, we found that the FFC has very strong correlation with $\mathrm{SH}(\mathrm{R}=0.809)$ and strong correlations with $\mathrm{BL}$ $(\mathrm{R}=0.769)$ and $\mathrm{PW}(\mathrm{R}=0.73)$. Results from the HFC show very strong correlation with $\mathrm{PW}(\mathrm{R}=0.826)$ and strong correlations with $\mathrm{BL}$ $(\mathrm{R}=0.775)$ and $\mathrm{SH}(\mathrm{R}=0.747)$. In the conclusion, the foot circumference is very useful to predict the elephant's size and can much reduce the mahouts' risk by minimizing interaction time needed in elephant's body measurement. For the field researcher, they are not necessary to meet with the elephants to predict the elephant's size in the wild.
\end{abstract}

Keywords: Body measurement, forefoot circumference, hindfoot circumference, linear-regression test, Sumatran elephant

\section{INTRODUCTION}

Sumatran elephant is the biggest wild animal in Indonesia, distributed in Sumatera Island with unpredictable behavior and a critically endangered status. Serious threats to Sumatran elephants are habitat loss, illegal hunting, and poaching (Sulandari and Zein 2012). Conservations had been done to minimize the risk of extinction. In conservation, body size is an important aspect because it is usually correlated with animals' fitness (Chiyo et al 2011). Knowledge of an individual's size can be used to give the right medical treatment or intervention (Berger 2012; Rayadin and Spehar 2015) because of problems like injuries, endoparasite and ectoparasite infections, and gastrointestinal disease in elephants are often occur in conservations (Miller et al 2015). Body size can also be used to look for niche differentiation in species
(Ramesh et al 2015) determining resources for feeding and trophic level (Heupel et al 2014) also for fitting GPS collars (Johansson et al 2013). However, trained elephants, especially males produce the oily, honey-like odor from their temporal gland during musth period (Hile and Hintz 1997). Adult males in musth develop more premating behaviors than non-musth younger males (Duer et al 2016). Such a condition increases the risk of the elephant keepers because the longer they are exposed to the animal, the more likely they are attacked. Elephants' interactions have occasionally brought unpleasant accidents, thereby loss of human lives, injuries and damages to properties (Radhakrishnan et al 2011). The same risk also threatens the conservationists who work in the elephant's natural habitat since they have direct contact with the elephants to predict the population size. To date, predicting elephant body weight from body measurement has been performed 
(Kanchanapangka et al 2007), however, research on predicting body size from other body part measurements is still limited. Therefore, measuring body size up to now still uses a direct contact method with lengthy and risky procedures. The risk increases when the habitat is very poor in quality and quantity. The risk increases when the habitat is very poor in quality, meaning the habitat has been damaged, from result such as: deforestation and fragmentation, and quantity, meaning the habitat contains vegetation and another biotic environment needed by the elephant less than normal habitat. Measuring 2.4-2.9 $\mathrm{m}$ tall and $3700-4500 \mathrm{~kg}$ weight, the elephants may incur fatal accidents to humans due to a small error handling from the human (Fowler and Mikota 2006). To reduce the risk of everybody who interacts with elephants, a special method to collect the main body size in a brief manner is urgently needed. Anatomically, one of the body parts has a specific ratio with other main body parameters that are frequently used in equations to predict weight such as body length, body height, and pelvic width (De Esteban-Trivigno and Köhler 2011). This research is conducted to find the correlation between foot circumference and another body measurement to gain certain formulas to estimate other body parameters using the foot circumference. Estimation method in measurement are easier to apply and have advantages in terms of practicality than direct measurement, although it is not more accurate (Soeharsono et al 2020). Accordingly, identification of the correlation between foot circumference and other body measurement variables will significantly reduce the time needed to predict the elephant's size. Moreover, animal welfare issues in terms of invasive activities due to the prolonged interaction with the animals can be prevented.

Similar research had been done by Chapman et al (2016) using non-Sumatran elephants in Myanmar with different sex and age, the research stated that using few parameters can decrease the errors between the real measurement and the measurement using the equation so that the equation can be used on the field. Here, we examine the relationship between different morphological measures (between foot circumference and the vital body

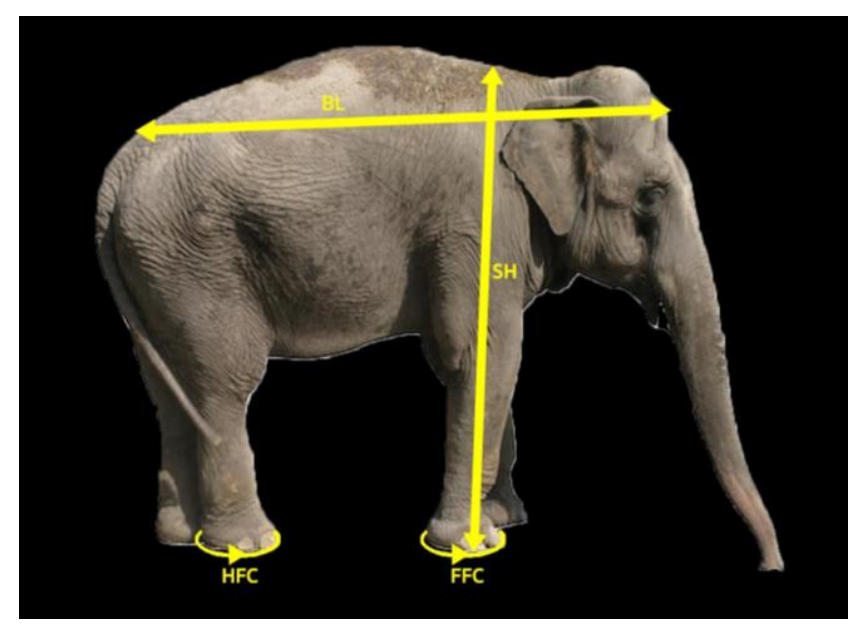

Figure 1. Sumatran elephants body measurements. FFC: forefoot circumference, HFC: hindfoot circumference, BL: body length, $\mathrm{SH}$ : shoulder height measurement guides size) in the Sumatran elephant in order to create an equation for predicting elephant size safely, reliably, and quickly.

\section{MATERIALS AND METHODS}

\section{Animals}

Fifty-three (53) male and female adult captive elephants inhabiting numerous locations at elephant rescue center in Aceh, PLG Duri Pekanbaru, Way Kambas, Lampung, and elephants at Indonesia Safari Park, Gembira Loka Zoo, and Borobudur Park. We only use adult elephants since they have already reached the maximum body size and proportion between some body part. In our present study, we assumed that bigger body size is bigger foot circumference, so we are not differentiating the equation between male and female elephants.

\section{Tools}

Measurement was done with two modified vernier calipers extending up to $200 \mathrm{~cm}$ and $400 \mathrm{~cm}$, and roll meter.

\section{Body measurements}

Measurement is carried out on body length, shoulder height, pelvic width, and foot circumference, both hindfoot and forefoot. Body length (BL) is measured starting from the frontest end of os frontal up to the base of the tail. Shoulder height ( $\mathrm{SH})$ is measured perpendicularly from the ground up to the highest shoulder point. Pelvic width (PW) is measured between tuber coxae dexter and tuber coxae sinister. Foot circumference is measured circularly on the most outer side on the distal aspect of foot (Kanchanapangka et al 2007). The measurement guides are shown in Figures 1 and 2. Body measurements are not carried on different sex (particularly differentiating between male and female). Elephants do have different body sizes regarding their sex, but proportionally there is no significant difference (such as comparison between the shoulder height and foot circumference or with other variables). It is evidenced in the result of measurements with tolerance levels below $13 \%$.

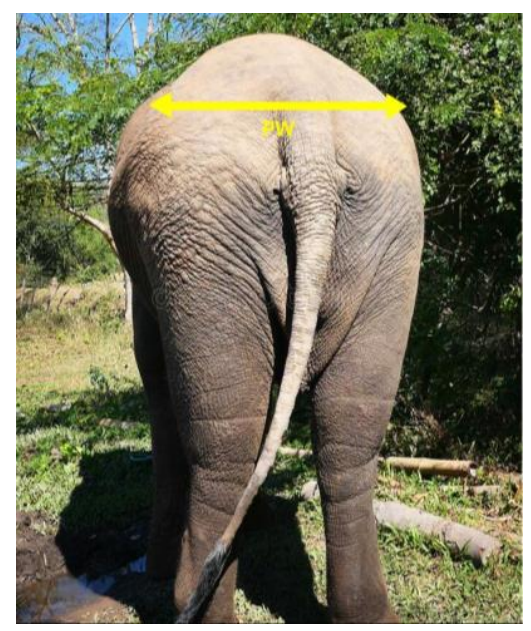

Figure 2. Sumatran elephants body measurements. PW: Pelvic Width measurement guide 
In some cases, captive elephants have an abnormal body size compared to the other group member of the same age. Abnormal body size is often caused by food problems. Elephants usually consume natural vegetation and cultivated crops (Das et al 2014). Elephants eat more dicots in dry season than in wet season (Koirala and Aryal 2016) and spend their time about $45 \%$ to $75 \%$ for foraging (Ahamed 2015). From our observation, minimum body size was found in some elephants with sub-dominant behavior. They tend to wait during feeding time until all of the aggressive elephants finished their food. In such a prolonged situation, it caused the food problem. To obtain a homogenous body size, it is recommended to modify the feeding management of the group by giving special attention to the sub-dominant elephants. Such phenomenon can occur to calf that is prematurely separated from the family and must survive with the other elephants after the parents die. To avoid high error of equation correlation, we exclude the abnormal morphological data from our calculation such as sub-dominant elephant mentioned above.

\section{Data analysis}

The measurement results were calculated with correlations and linear regression tests. Results gained from measurement of body and foot circumference then processed with linear regression. Linear regression predicts the value of one variable (dependent variable/ y variable) based on the value of another variable (independent variable/ x variable) (Kumari and Yadav 2018).

$$
\text { Linear formulas }=\mathrm{Y}=\mathrm{a}+\mathrm{bx}
$$

The forefoot circumference (FFC) and the hindfoot circumference (HFC) were considered as a variable to be explained (dependent variable), the explanatory variables being $\mathrm{BL}, \mathrm{SH}$, and $\mathrm{PW}$. The different FFC and HFC prediction formulas were compared. The determination coefficients (R2) of the $\mathrm{BL}, \mathrm{SH}$, and $\mathrm{PW}$ prediction equations were determined using simple linear regressions.

\section{RESULTS AND DISCUSSION}

Using BL, SH, and PW in correlation to both FFC and HFC resulting in measurement demonstrated in Table 1 and Table 2. The averages of each body measurement are: FFC $=119.77+10.8 \mathrm{~cm} ; \mathrm{HFC}=111.42+12.59 \mathrm{~cm} ; \mathrm{BL}=$ $274.85+18.78 \mathrm{~cm} ; \mathrm{SH}=215.72+14.67 \mathrm{~cm} ; \mathrm{PW}=110.88$ $+10.54 \mathrm{~cm}$. Correlation coefficient (R) between FFC and BL (0.769); and PW (0.73) is strong, whereas the R between FFC and SH is very strong (0.809). R between HFC and BL (0.775); and SH (0.747) are strong, whereas the R between HFC and PW (0.826) is very strong. The expression of the FFC and HFC according to these measurements is illustrated by different graphs (Figure 3Figure 8). These figures show a strong dispersion of the point cloud between FFC and BL, PW (Figure 3, Figure 5); and HFC and BL, SH (Figure 6, Figure 7), and an almost linear distribution of the point cloud between FFC and $\mathrm{SH}$ (Figure 4); HFC and PW (Figure 8).

\section{Correlation between FFC and BL}

The linear line between the circumference of the forefoot and body length on the Sumatran elephant shows a linear line that is positively correlated (Figure 3). Correlation coefficient (R) between FFC and BL is 0.775, the correlation between data is strong. Determination coefficient (R2) FFC and BL is 0.591, meaning BL is affected by FFC by $59,1 \%$. Formula obtained from the linear regression test is:

$$
y=1.3376 x+114.65
$$

Compared data (between the measured and equation result) shows that the tolerance level is all below $13 \%$. Tolerance level ranges from $0.04 \%$ up to $7.81 \%$. The data calculation result validates the equation; hence the equation can be applied.

\section{Correlation between FFC and SH}

The linear line between the circumference of the forefoot and shoulder height on the Sumatran elephant shows a linear line that is positively correlated (Figure 4). Correlation coefficient (R) between FFC and $\mathrm{SH}$ is 0.775 , the correlation between data is strong. Correlation coefficient (R) between FFC and SH is 0.809 , the correlation between data is very strong. Determination coefficient (R2) of FFC and $\mathrm{SH}$ is 0.655 , meaning $\mathrm{SH}$ is affected by FFC by $65.5 \%$. Formula obtained from the linear regression test is:

$$
y=1.17 x+75.734
$$

Compared data (between the measured and equation result) shows that the tolerance level is all below $13 \%$. Tolerance level ranges from $0.14 \%$ up to $7.9 \%$. The tolerance rate below $13 \%$ is the result of comparing real measurements from the elephant, with measurements gathered from the equation. The data calculation result validates the equation; hence the equation can be applied.

Table 1. Correlation between FFC and other variables (BL, SH, PW)

\begin{tabular}{lc}
\hline Variables & Correlation coefficient \\
\hline BL & 0.769 \\
SH & 0.809 \\
PW & 0.73 \\
\hline
\end{tabular}

Table 2. Correlation between HFC and other variables (BL, SH, PW)

\begin{tabular}{lc}
\hline Variables & Correlation coefficient \\
\hline BL & 0.775 \\
SH & 0.747 \\
PW & 0.826 \\
\hline
\end{tabular}




\section{Correlation between FFC and PW}

The linear line between the circumference of the forefoot and pelvic width on the Sumatran elephant shows a linear line that is positively correlated (Figure 5). Correlation coefficient (R) between FFC and PW is 0.73, the correlation between data is strong. Determination coefficient (R2) of FFC and PW is 0.534 , meaning PW is affected by FFC by $53.4 \%$. Formula obtained from the linear regression test is:

$$
y=0.5516 x+48.201
$$

Compared data (between the measured and equation result) shows that the tolerance level is all below $13 \%$. Tolerance level ranges from $0.08 \%$ up to $8.94 \%$. The data calculation result validates the equation; hence the equation can be applied.

\section{Correlation between HFC and BL}

The linear line between the circumference of the hindfoot and body length on the Sumatran elephant shows a linear line that is positively correlated (Figure 6). Correlation coefficient (R) between HFC and BL is 0.769, the correlation between data is strong. Determination coefficient (R2) of FFC and BL is 0.601 , meaning BL is affected by FFC by $60.1 \%$ (Table 3 ). Formula obtained from the linear regression test is

$$
y=1.573 x+101.28
$$

Compared data (between the measured and equation result) shows that the tolerance level is all below $13 \%$. Tolerance level ranges from $0.17 \%$ up to $10.27 \%$. The data calculation result validates the equation; hence the equation can be applied.

\section{Correlation between HFC and SH}

The linear line between the circumference of the hindfoot and shoulder height on the Sumatran elephant shows a linear line that is positively correlated (Figure 7). Correlation coefficient (R) between HFC and SH is 0.747 , the correlation between data is strong. Determination

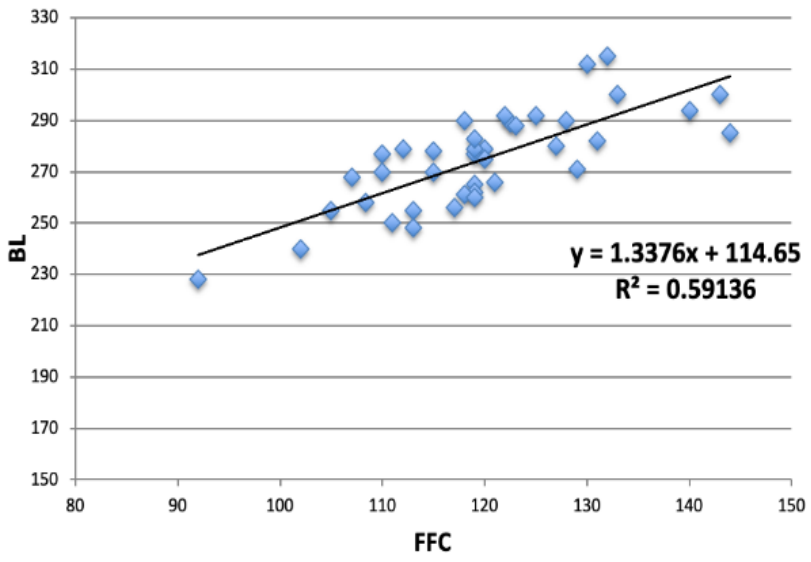

Figure 3. Linear regression graph between FFC and BL coefficient (R2) of FFC and $\mathrm{SH}$ is 0.558 , meaning $\mathrm{SH}$ is affected by HFC by $55.8 \%$ (Table 4). Formula obtained from the linear regression test is:

$$
y=0.8944 x+118.29
$$

Compared data (between the measured and equation result) shows that the tolerance level is all below $13 \%$. Tolerance level ranges from $0.21 \%$ up to $8.56 \%$. The data calculation result validates the equation; hence the equation can be applied.

\section{Correlation between HFC and PW}

The linear line between the circumference of the hindfoot and pelvic width on the Sumatran elephant shows a linear line that is positively correlated (Figure 8). Correlation coefficient (R) between HFC and PW is 0.826, the correlation between data is very strong. Determination coefficient (R2) of HFC and PW is 0.6823 , meaning PW is affected by HFC by $68.23 \%$. (Table 5 ). Formula obtained from the linear regression test is:

$$
y=0.7246 x+30.472
$$

Compared data (between the measured and equation result) shows that the tolerance level is all below $13 \%$. Tolerance level ranges from $0.29 \%$ up to $9.64 \%$. The data calculation result validates the equation; hence the equation can be applied.

Table 3. Formulas for estimating body length, shoulder height, and pelvic width

\begin{tabular}{lclc}
\hline & $\begin{array}{c}\text { Variables } \\
(\mathbf{x})\end{array}$ & \multicolumn{1}{c}{ Formulas } & R2 \\
\hline Body length & FFC & $y=1.3376 x+114.65$ & 0.591 \\
& HFC & $y=1.573 x+101.28$ & 0.601 \\
& & & \\
Shoulder & FFC & $y=1.17 x+75.734$. & 0.655 \\
height & HFC & $y=0.8944 x+118.29$ & 0.558 \\
& & & \\
Pelvic width & FFC & $y=0.5516 x+48.201$ & 0.534 \\
& HFC & $y=0.7246 x+30.472$ & 0.6823 \\
\hline
\end{tabular}

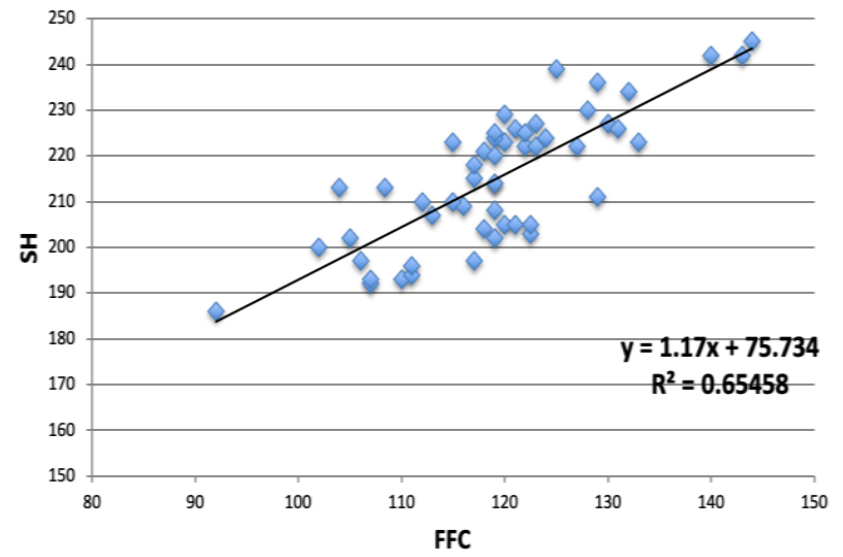

Figure 4. Linear regression graph between $\mathrm{FFC}$ and $\mathrm{SH}$ 


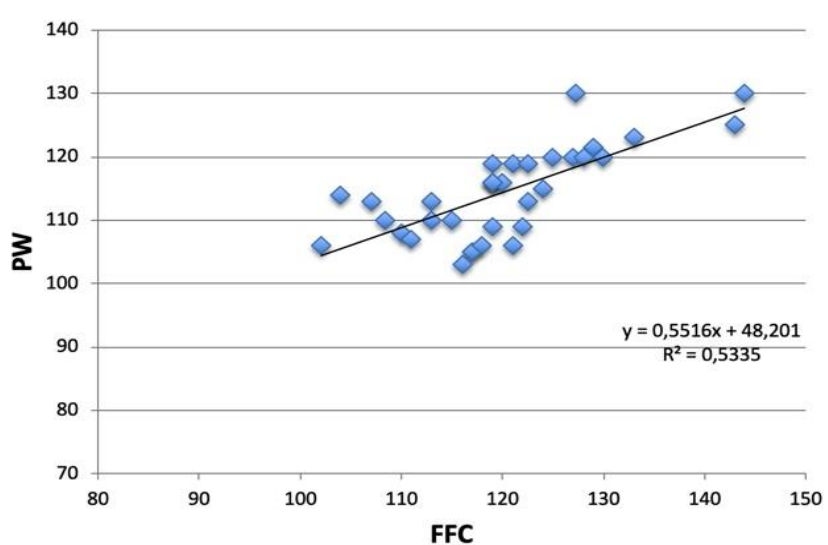

Figure 5. Linear regression graph between FFC and PW

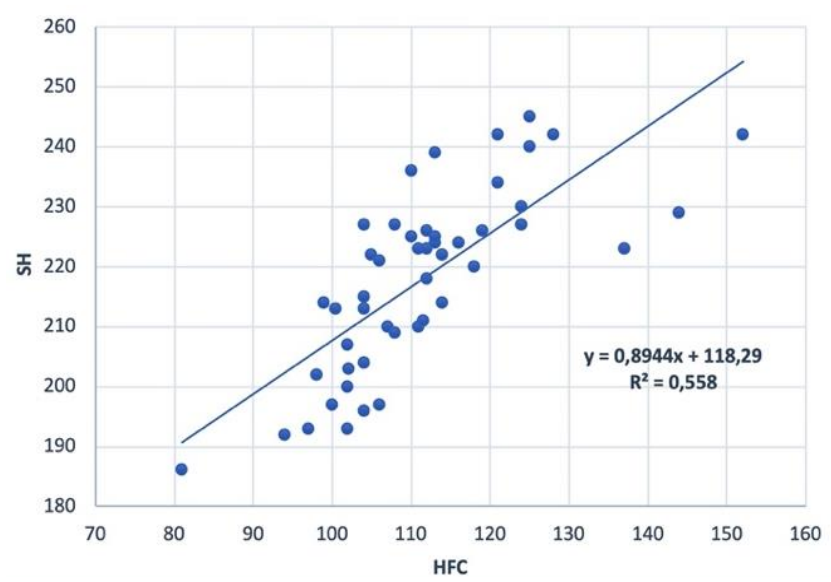

Figure 7. Linear regression graph between HFC and SH.

\section{Discussion}

Being big and heavy, elephants modified their long bone of the appendicular skeleton into a massive structure with no marrow cavities and in almost vertical position. These modifications resulted in a stronger bone and a more stable position to support body weight (Fowler and Mikota 2006). Based on our statistical analysis, isometrically the correlation powers among the measured variables ranged between low $(\mathrm{R} 2<0.6)$ and moderate $(0.6<\mathrm{R} 2<0.8)$. The accepted error for our anatomical study report referring to Hile and Hintz (1997) and Schulte (2006), is less than $15 \%$.

Through the research conducted, results show that it is possible to obtain elephant body measurements using only formulas. The objective of the research is fulfilled, since the fault tolerance is all below 13\%, meaning all the formulas are applicable for mahouts to measure the elephant. All of the $\mathrm{R}$ is above 0.73 , therefore all the correlations are strong and therefore it makes reliable formulas. Body Length (BL), calculated with forefoot and hindfoot circumference, result in strong correlation $(\mathrm{R}=0.769$, Table $1 ; \mathrm{R}=0.775$, Table 2$)$ and the obtained formulas are shown in Table 3. Therefore, the more reliable formula to obtain BL is using HFC.

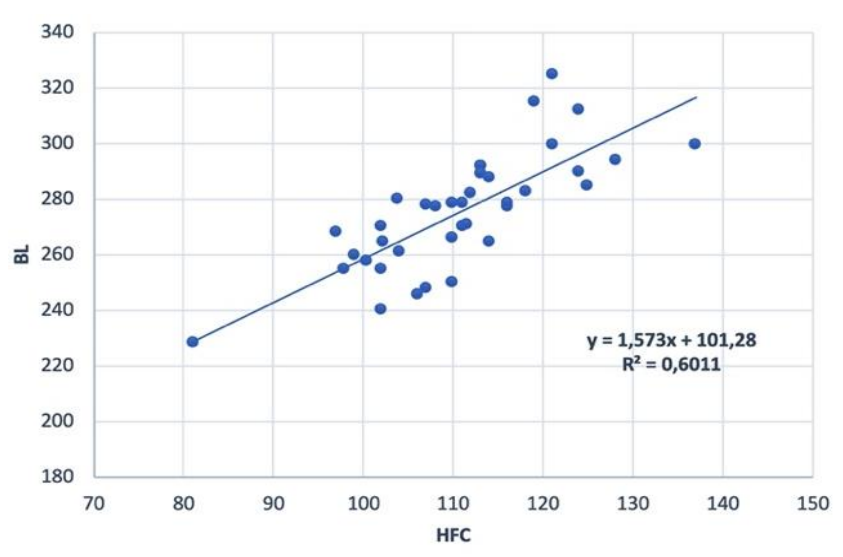

Figure 6. Linear regression graph between HFC and BL

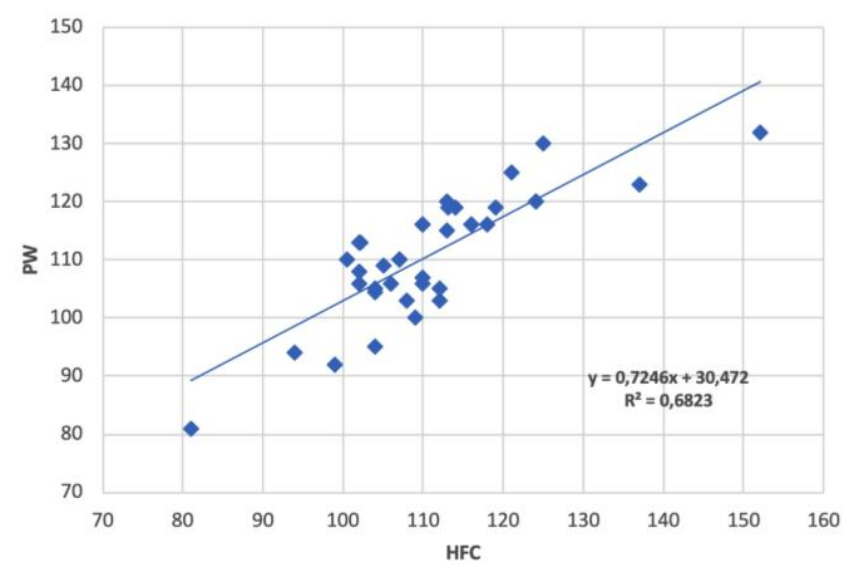

Figure 8. Linear regression graph between HFC and PW.

Body Length (BL), calculated with forefoot and hindfoot circumference, result in strong correlation ( $\mathrm{R}=0.769$, Table $1 ; \mathrm{R}=0.775$, Table 2 ), and the obtained formulas are shown in Table 3. Therefore, the more reliable formula to obtain BL is using HFC.

In conclusion, the most reliable formula in result of this research are: $y=1.573 x+101.28$ [5] (formula obtained from BL and HFC); $y=1.17 x+75.734$ [3] (formula obtained from SH and FFC); $y=0.7246 x+30.472$ [7] (formula obtained from $\mathrm{PW}$ and HFC). The formulas gained from the research are all applicable for mahouts in the field. Therefore the objective of the research, to minimize mahout's work risk, is achieved.

\section{ACKNOWLEDGEMENTS}

We would like to express our gratitude to Taman Safari Indonesia Bogor, Taman Safari Indonesia Prigen, Gembira Loka Zoo, Borobudur Park, Elephant Training Center Way Kambas, and Elephant Training Center Duri and Minas Riau. Special thanks to the Indonesian Ministry of Environment and Forestry that give us permission to 
collecting Sumatran elephant sample and Veterinary Society for Sumatran Wildlife Conservation (VESSWIC) for the support to get the permission and collecting samples in the field. This study was supported by Biodiversity Program from Faculty of Veterinary Medicine, Universitas Gadjah Mada, Yogyakarta, Indonesia. Our warmest appreciation also addressed to all of the elephant's keepers for their support and kind helping during data collection.

\section{REFERENCES}

Ahamed AMR. 2015. Activity Time Budget of the Asian Elephant (Elephas maximus Linn.) in the Wild. Trends Biosci 8: 3024-3028.

Berger J. 2012. Estimation of body-size traits by photogrammetry in large mammals to inform conservation. Conserv Biol 26: 769-777. DOI: 10.1111/j.1523-1739.2012.01896.x.

Chapman SN, Mumby HS, Crawley JAH, Mar KU, Htut W, Thura, Soe A, Aung HH, Lummaa V. 2016. How big is it really? assessing the efficacy of indirect estimates of body size in Asian elephants. PLoS ONE 11: e0150533. DOI:10.1371/journal. pone.0150533.

Chiyo P, Lee P, Moss C, Archie E, Hollister-Smith J, Alberts S. 2011. No risk, no gain: effects of crop-raiding and genetic diversity on body size in male elephants. Behav Ecol 22: 552-558. DOI 10.1093/BEHECO/ARR016.

Das BJ, Saikia BN, Baruah KK, Bora A, Bora M. 2014. Nutritional evaluation of fodder, its preference and crop-raiding by wild Asian elephant (Elephas maximus) in Sonitpur District of Assam, India, $\begin{array}{lllll}\text { Veterinary World } 7 & (12): & 1082-1089 . & \text { DOI: }\end{array}$ 10.14202/vetworld.2014.1082-1089.

De Esteban-Trivigno S, Köhler M. 2011. New equations for body mass estimation in bovids: Testing some procedures when constructing regression functions. Mamm Biol 76: 755-761. DOI: 10.1016/j.mambio.2011.07.004.

Duer C, Tomasi T, Abramson C. 2016. Reproductive endocrinology and musth indicators in a captive Asian elephant (Elephas maximus) Psychol Rep 119 (3): 839-860. DOI: 10.1177/0033294116667092.

Fowler ME, Mikota, SK. 2006. Biology, Medicine and Surgical of Elephant. Blackwell Publishing, USA. DOI:10.1002/9780470344484.
Heupel MR, Knip DM, Simpfendorfer CA, Dulvy NK. 2014. Sizing up the ecological role of sharks as predators. Mar Ecol Prog Ser 2014 495: 291-298. DOI: 10.3354/meps 10597.

Hile ME, Hintz HF, Erb HN. 1997. Predicting body weight from body measurements in Asian elephants (Elephas maximus). J Zoo Wildl Med 28 (4): 424-427.

Johansson Ö, Malmsten J, Mishra C, Lkhagvajav P, McCarthy T. 2013. Reversible immobilization of free-ranging snow leopards (Panthera uncia) with a combination of Medetomidine and Tiletamine-Zolazepam. J Wildl Dis 49: 338-346. DOI: 10.7589/2012-02-049.

Kanchanapangka S, Supawong S, Koedlab K, Kaewpannarai J, Khawnual P, Tummaruk P, Sajjarengpong K. 2007. Body weight formulation in Asian elephant. Thai J Vet Med 37 (1): 49-58

Koirala R, Aryal A. 2016. Feeding preferences of the Asian elephant (Elephas maximus) in Nepal. BMC Ecol 16 (1): 54. DOI: 10.1186/s12898-016-0105-9.

Kumari K, Yadav S. 2018. Linear regression analysis study. J Practice Cardiovas Sci 2018 (4): 33-36. DOI: 10.4103/jpcs.jpcs_8_18.

Miller D, Jackson B, Riddle H, Schmitt D, Miller T. 2015. Elephant (Elephas maximus) health and management in Asia: Variations in veterinary perspectives. Vet Med Intl 2015: 614690. DOI: $10.1155 / 2015 / 614690$.

Radhakrishnan MC, Rajeev TS, Radhakrishnan CN. 2011. Job risks and problems of mahouts (elephant keepers) in Kerala, South India. Gajah 34: 18-19.

Ramesh T, Kalle R, Sankar K, Qureshi Q. 2015. Role of body size in activity budgets of mammals in the Western Ghats of India. J Trop Ecol 31: 315-323. DOI: 10.1017/S0266467415000188.

Rayadin Y, Spehar SN. 2015. Body mass of wild Bornean orangutans living in human-dominated landscapes: Implications for understanding their ecology and conservation. Am J Phys Anthropol 157 (2): 339-346. DOI: 10.1002/ajpa.22709.

Soeharsono S, Mulyati S, Utama S, Wurlina W, Srianto P, Restiadi TI, Mustofa I. 2020. Prediction of daily milk production from the linear body and udder morphometry in Holstein Friesian dairy cows, Vet World 13 (3): 471-477. DOI: 10.14202/vetworld.2020.471-477.

Sulandari S, Zein MSA. 2012. Mitochondrial DNA variation of the Sumatran elephant populations in Sumatra, Indonesia. Biotropia 19 (2): 92-102. DOI: 10.11598/btb.2012.19.2.250.

Schulte BA. 2006. Behavior and Social Live in Biology Medicine, and Surgery of Elephants. Blackwell Publishing, IOWA. DOI: 10.1002/9780470344484.ch4. 